\title{
Behaviour of the fellow eye in acute angle-closure glaucoma
}

\author{
R. S. EDWARDS \\ From the Birmingham and Midland Eye Hospital, Church Street, Birmingham B3 2NS
}

SUMmARY A retrospective study of 245 fellow eyes of patients admitted in primary acute angleclosure glaucoma (ACG) is presented. Twenty-five (10.2\%) had acute ACG in the fellow eye on presentation. Of the remaining $220,33(15 \%)$ subsequently developed acute ACG before prophylactic surgery was performed. Possible predisposing factors were analysed. The main findings were that acute ACG in the fellow eye occurred most frequently in hospital, or during the first month after discharge if prophylactic surgery was not performed. The instillation of mydriatics in the operated eye increased the risk to the fellow eye. Pilocarpine and carbonic anhydrase inhibitors confer the best protection on the fellow eye, but no medical regimen entirely prevented an attack of acute ACG in the fellow eye.

The aim of this retrospective study was to determine the behaviour of the fellow eye in patients admitted with primary acute angle-closure glaucoma (ACG). The possible factors which might precipitate acute ACG in this eye have been studied.

The consequences of an attack of acute ACG are well documented. They include peripheral field loss from ischaemic damage to the optic nerve head, ${ }^{1}$ some loss of visual acuity ${ }^{2}$ even if the attack is treated at its inception, ${ }^{3}$ and a lowering of endothelial cell density in attacks which last 3 days or more. ${ }^{4}$ It is therefore advisable to prevent an attack of acute ACG in the fellow eye whenever possible.

\section{Patients and methods}

Two hundred and forty-five patients admitted as emergencies to the Birmingham and Midland Eye Hospital in primary acute ACG during the period of January 1972 to December 1978 were studied. Patients with chronic angle closure were excluded, and all the fellow eyes had narrow angles. One hundred and seventy (69\%) were female and 75 (31\%) male, their mean age being 66.8 years.

The incidence and timing of acute ACG attacks in the fellow eye were studied and the risk to the fellow eye during the periods outlined in Table 1 has been expressed in terms of attack rate, or the number of attacks of acute ACG per 100 fellow eyes per day.

Correspondence to Mr R. S. Edwards
Attack rate $=\frac{\text { percentage of fellow eyes developing acute ACG }}{\text { number of days in period studied }}$

The following factors were investigated: the general health and systemic medication of all patients at presentation; the topical and systemic medication prescribed pre- and postoperatively, on discharge, and during the follow-up period.

Although individual treatment regimens varied greatly, it was possible to group them according to the strength and frequency of pilocarpine instillation in the fellow eye and according to whether or not a mydriatic was instilled in the operated eye. Mydriatics to the operated eye included atropine 1\%, Mydrilate (cyclopentolate $\mathrm{HCl}) 1 \%$, phenylephrine $10 \%$, and homatropine $2 \%$ instilled one to 3 times a day. Comparisons were made in each case between patients whose fellow eye developed acute ACG and patients whose fellow eye escaped acute ACG.

\section{Results}

Incidence of attacks. Fifty-eight patients (23.6\%) developed an attack of acute ACG in the fellow eye

Table 1 Surgical management of the fellow eye

\begin{tabular}{lr}
\hline Management & No. of patients \\
\hline Surgery simultaneously with acute eye & 51 \\
Separate operation while still in hospital & 142 \\
Discharged from hospital without surgery & 52 \\
Total & 245 \\
\hline
\end{tabular}


Table 2 Details of fellow eyes developing acute attacks

\begin{tabular}{|c|c|c|c|c|}
\hline Timing & $\begin{array}{l}\text { Number prior } \\
\text { to surgery }\end{array}$ & $\begin{array}{l}\text { Number developing } \\
\text { acute } A C G\end{array}$ & Percent & $\begin{array}{l}\text { Attack rate } \\
\text { (no. of attacks per } 100 \\
\text { eyes per day) }\end{array}$ \\
\hline \multirow{6}{*}{$\begin{array}{l}\text { At or prior to admission } \\
\text { Up to acute eye surgery or } \\
\text { discharge; mean } 5 \cdot 2 \text { days } \\
\text { Between acute eye surgery and } \\
\text { fellow eye surgery or discharge; } \\
\text { mean } 6 \cdot 7 \text { days } \\
0-1 \text { month after discharge } \\
1-12 \text { months after discharge } \\
12-48 \text { months after discharge } \\
\text { (mean } 26 \text { months) }\end{array}$} & 245 & 25 & $10 \cdot 2$ & - \\
\hline & 220 & 9 & $4 \cdot 1$ & 0.79 \\
\hline & 187 & 14 & $7 \cdot 5$ & $1 \cdot 12$ \\
\hline & 52 & 7 & $13 \cdot 4$ & 0.48 \\
\hline & 35 & 2 & $\begin{array}{r}5 \cdot 7 \\
\text {. }\end{array}$ & 0.02 \\
\hline & 14 & 1 & $7 \cdot 1$ & 0.02 \\
\hline
\end{tabular}

before it could be treated surgically. Forty-eight patients $(19.5 \%)$ developed acute ACG in the fellow eye either by the time they were admitted or during their stay in hospital. Ten patients developed acute ACG following discharge from hospital (7 of these during the first month after discharge). Twenty-nine of the 52 patients discharged from hospital without surgery to the fellow eye did eventually undergo surgery to that eye, 10 following an attack of acute ACG and 19 electively.

Timing of attacks. The timing of fellow eye ACG attacks is detailed in Table 2 . Twenty-five patients
(10.2\%) had bilateral acute ACG on admission, and 7 of these were induced by a mydriatic. Of the remaining 220 patients 9 developed acute ACG in the fellow eye prior to surgery on the first eye, and 14 more developed similar attacks in the early postoperative period. The greatest susceptibility to acute ACG in the fellow eye is from the time of admission up to the first month after discharge, the first postoperative week being the most critical period. This increased susceptibility is illustrated by the high number of attacks per 100 eyes per day (attack rate) during this period.

Table 3 Effect of treatment on the incidence of acute ACG in the fellow eye prior to initial surgery (mean $5 \cdot 2$ days)

\begin{tabular}{lllll}
\hline Regimen of treatment & $\begin{array}{l}\text { No. of } \\
\text { eyes studied }\end{array}$ & $\begin{array}{l}\text { No. developing } \\
\text { acute ACG }\end{array}$ & $\begin{array}{l}\text { Percent } \\
\text { attacks per 100 eyes } \\
\text { per day) }\end{array}$ \\
\hline CA inhib+pilo* & 56 & 1 & $1 \cdot 8$ & $0 \cdot 35$ \\
Pilo 2\% or stronger 4 times a day & 63 & 2 & $3 \cdot 2$ & $0 \cdot 62$ \\
Other pilo regimen & 91 & 4 & $4 \cdot 3$ & $0 \cdot 83$ \\
No treatment & 10 & 2 & $20 \cdot 0$ & $3 \cdot 85$ \\
Total & 220 & 9 & $4 \cdot 1$ & $0 \cdot 79$ \\
\hline
\end{tabular}

*CA Inhib=carbonic anhydrase inhibitors. Pilo=pilocarpine drops.

Table 4 Effect of treatment on the incidence of acute ACG between first eye surgery and fellow eye surgery or discharge (mean 6.7 days)

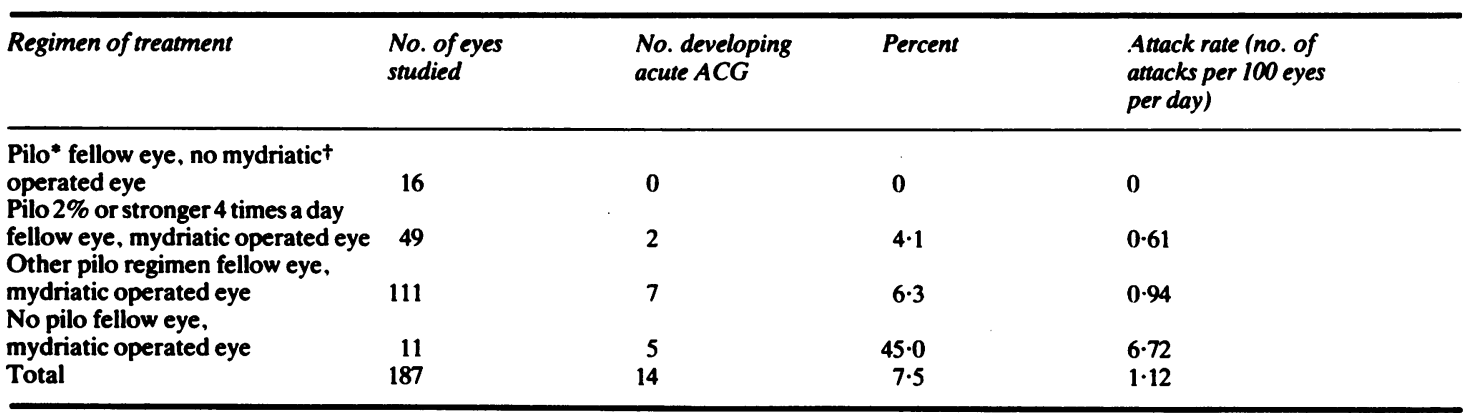

*Pilo=pilocarpine drops.

+Mydriatics prescribed included $2 \%$ homatropine, $1 \%$ atropine, $1 \%$ cyclopentolate, $10 \%$ phenylephrine. These were all associated with at least one acute ACG attack in a fellow eye. 
Patient's general condition. General systemic disorders did not appear to have any predisposing effect, but drugs with anticholinergic effects may have been a factor. The numbers, however, were too small to draw definite conclusions.

OPHTHALMIC TREATMENT

Preoperatively (Table 3). In the interval between admission and surgery to the first eye patients who received carbonic anhydrase inhibitors (in this sample acetazolamide $250 \mathrm{mg} 2$ to 4 times a day) plus pilocarpine drops to both eyes appeared less liable to develop acute ACG in the fellow eye, but there was one exception. Two of the 10 fellow eyes receiving no treatment developed acute ACG, representing an attack rate of 3.85 attacks per 100 eyes per day. If the fellow eye received pilocarpine drops, the risk of an acute attack appeared to be less.

Early postoperative period (Table 4). Fourteen attacks occurred during the period between surgery to the acute eye and surgery to the fellow eye, or discharge without surgery. Of these, 4 occurred on the first postoperative day. All these patients had had general anaesthesia, and apart from intramuscular atropine premedication there was no other common factor in their management.

In relation to postoperative medication, the results in Table 4 show a much higher incidence of acute ACG in the fellow eye when mydriatics had been prescribed for the operated eye and no prophylaxis for the fellow eye. Conversely no acute ACG occurred in fellow eyes if mydriatics were not used on the operated eve.

First month of follow-up (Table 5). Seven out of 52 fellow eves developed acute ACG during this period, and these were confined to the 38 patients receiving mydriatic in the operated eye. None of the 14 patients receiving no mydriatic to the operated eye developed acute ACG (all patients were on pilocarpine to the fellow eye).

Subsequent follow-up. Once unoperated eyes had been followed up for more than one month, and mydriatic drops to the operated eye had been stopped, the liability to an acute ACG attack became less (Table 1). Nonetheless, attacks did occur up to 4 years after initial admission.

\section{Discussion}

The sample of patients studied is representative of patients presenting with acute ACG. The 2:1 female preponderance and the mean age in the mid $60 \mathrm{~s}$ is consistent with the many previous studies of this condition. The findings of this study confirm Lowe's observation $^{5}$ that no medical regimen guarantees freedom from an attack of acute ACG in the fellow eye.

INCIDENCE AND TIMING OF FELLOW EYE ATTACKS Acute ACG in the fellow eye occurs most frequently during the period between the initial onset of symptoms in the acute eye and the end of the first month of out patient follow up. Table 2 illustrates this tendency to early involvement of the fellow eye. Eighteen attacks occurred on or prior to admission without being provoked by mydriatics, and a further 9 occurred in hospital before any surgery was performed or any mydriatic treatment prescribed. Twenty-seven fellow eyes (11\% total) therefore developed acute ACG early without mydriatic being implicated. However, 7 patients presented with bilateral acute ACG induced by mydriatics. and postoperative treatment with mydriatics to the acute eve resulted in a higher incidence of acute ACC in unoperated fellow eyes when not protected by miotics. This emphasises the bilateral nature of the condition, but also that the use of midriation to the operated eye constitutes an additional risk fictor.

MANAGEMENT OF THE FELLOW H

Many studies, including recent serics he snow and Playfair and Watson, ${ }^{7}$ have emphasised the value of prophylactic peripheral iridectomy for the fellow eve.

As regards the timing of this procedure, the results of this study would favour bilateral simultaneous surgery on the acute and the fellow eye as the only means of avoiding acute ACG occurring in the fellow eye postoperatively. The principal arguments against

Table 5 Effect of treatment on incidence of acute ACG in the fellow eye in first month after discharge

\begin{tabular}{|c|c|c|c|c|}
\hline Regimen of treatment & $\begin{array}{l}\text { No. of eyes } \\
\text { studied }\end{array}$ & $\begin{array}{l}\text { No. developing } \\
\text { acute ACG }\end{array}$ & Percent & $\begin{array}{l}\text { Attack rate (no. of } \\
\text { attacks per } 100 \\
\text { eyes per day) }\end{array}$ \\
\hline $\begin{array}{l}\text { Pilo fellow eye, no mydriatic } \\
\text { operated eye } \\
\text { Pilo } 2 \% \text { or stronger } 4 \text { times a day }\end{array}$ & 14 & 0 & 0 & 0 \\
\hline $\begin{array}{l}\text { fellow eye, mydriatic operated eye } \\
\text { Other pilo regimens fellow eye. }\end{array}$ & 14 & 3 & $21 \cdot 4$ & $0 \cdot 76$ \\
\hline mydriatic operated eye & 24 & 4 & $16 \cdot 7$ & $0 \cdot 60$ \\
\hline Total & 52 & 7 & $13 \cdot 4$ & $0 \cdot 48$ \\
\hline
\end{tabular}


this would be the risk of endophthalmitis or malignant glaucoma occurring bilaterally. However, none of the 51 patients submitted to simultaneous bilateral surgery had either of these complications; nor did they occur in any of the patients treated surgically on separate occasions.

However, in view of the possible disastrous consequences of malignant glaucoma or endophthalmitis occurring bilaterally, however infrequently, some surgeons would still prefer not to perform bilateral simultaneous surgery on the acute and the fellow eye, and surgery on the fellow eye is occasionally postponed for various reasons. Therefore the question remains how best to treat the fellow eye until this is performed. Carbonic anhydrase inhibitors do appear to have a weak protective effect, and this would be consistent with their established place in the initial treatment of acute ACG.

Pilocarpine appears to have a protective effect when compared with no prophylactic treatment, especially if a mydriatic is used in the operated eye. Aqueous pilocarpine is effective only for 6 hours whatever its strength, so a frequency of instillation of 4 times a day would be logical. However, no individual pilocarpine regimen conferred a significantly greater protective effect in this series.

An increased risk to the fellow eye is caused by the instillation of mydriatic in the operated eye. This was true whether the patient was in hospital or at home. It is unlikely that enough topically applied mydriatic is absorbed systemically to cause an attack of acute ACG in the fellow eye, and it is more likely that mydriatic is either mistakenly applied to the fellow eye or is inadvertently transferred to the fellow eye by rubbing both eyes in turn. The acute eye often requires mydriatic treatment postoperatively, and, as this puts the fellow eye at risk from acute ACG, surgery to that eye should be performed as soon as possible. If the patient has to go home prior to prophylactic surgery, mydriatics in the operated eye should be avoided where possible.

\section{CONCLUSIONS}

Acute primary ACG is potentially a bilateral condition with early involvement of the second eye being frequent. In these patients the fellow eye will be at risk from a similar attack no matter what medical treatment is given. There is a high incidence of acute ACG in the fellow eye when the patient is in hospital, and the risk is further increased by mydriatic treatment to the operated eye, particularly if the fellow eye is not protected by pilocarpine. Prophylactic peripheral iridectomy on the fellow eye should be done either simultaneously or within a few days of surgery on the acute eye, and it is not advisable to send the patient home or postpone surgery longer than is absolutely necessary. During the interval before surgery to the fellow eye pilocarpine drops instilled 6 hourly appear to be the safest treatment, and supplementary acetazolamide $250 \mathrm{mg} 2$ to 4 times a day may possibly confer additional protection.

I thank the consultant surgeons of the Birmingham and Midland Eye Hospital for permission to study their patients, and Miss Eagling and Mr O'Neill for their helpful advice and encouragement.

\section{References}

1 McNaught EI, Rennie A, MaClure E, Chisholm IA. Pattern of visual damage after acute angle closure glaucoma. Trans Ophthalmol Soc UK 1974; 94: 406-15.

2 Lloyd-Jones D. Ocular morbidity in closed angle glaucoma. Res Clin Forums 1980; 2: 77-83.

3 Hillman JS. Acute closed-angle glaucoma: an investigation into the effect of delay in treatment. BrJ Ophthalmol 1979; 63: 817-21.

4 Setälä K. Corneal endothelial cell density after an attack of acute glaucoma. Acta Ophthalmol (Kbh) 1979; 57: 1004-13.

5 Lowe RF. Acute angle closure glaucoma: the second eye: an analysis of 200 cases. Br J Ophthalmol 1962; 46: 641-50.

6 Snow JT. Value of prophylactic peripheral iridectomy on the second eye in angle closure glaucoma. Trans Ophthalmol Soc UK 1977; 97: 189-91.

7 Playfair TJ, Watson PG. Management of acute primary angleclosure glaucoma: a long-term follow up on the results of peripheral iridectomy used as an initial procedure. $B r J$ Ophthalmol 1979; 63: 17-20. 